\title{
Health agencies overwhelmed by Syrian crisis
}

$\mathrm{H}$ umanitarian agencies providing health services to Syrian refugees are rapidly being overwhelmed by the need - and running short of funds. Since the civil war began in Syria in 2011, more than four million people have fled to neighbouring Iraq, Lebanon and Jordan; now as those countries reach capacity, half a million refugees are seeking asylum in Europe.

Several humanitarian agencies providing health care to refugees in Lebanon, Jordan and Iraq have recently been forced to scale back services because of a lack of funding.

The Office of the United Nations High Commissioner for Refugees (UNHCR) has only $37 \%$ of the funding it needs and says that if it doesn't fill the gap soon, 10000 people will not have access to emergency health care. Furio de Angelis, the UNHCR representative in Canada, says they will have to begin prioritizing patients.

The national health systems of neighbouring countries are also overburdened, says Jeffrey Bates, chief of communications for the United Nations Children's Fund (UNICEF) in Iraq. Many Syrian refugees live with local populations in urban centres and rely on host nations' health systems rather than aid agencies.

UNICEF is struggling as well. When Bates first arrived in Iraq in 2013, UNICEF provided Syrians and the general population with immunization, education, protection and screening for malnutrition.

The tipping point came in June 2014, when 500000 refugees arrived in Iraq; since then that number has tripled. "In the last year we've gone from a program that was emergency- and development-focused to one that is almost purely emergency."

UNICEF appealed for \$624 million to fund its programs for children but only $49 \%$ of that goal has been met. Bates says they will have to start scaling back services when they should be scaling up.

Based on reports from before the civil war began, chronic disease once caused

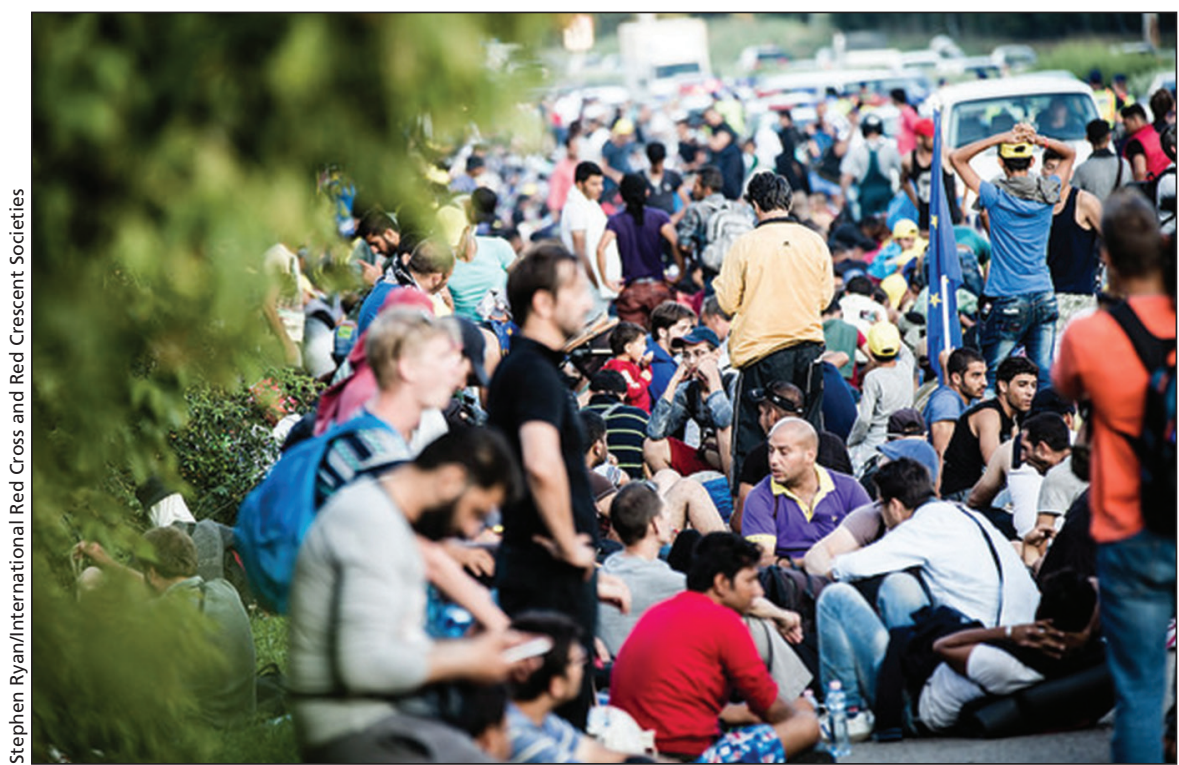

Humanitarian agencies' resources are stretched as the Syrian refugee crisis escalates and migrates into Europe.

over $75 \%$ of deaths. But, nowadays, many Syrians with chronic diseases don't get the treatment they need. This is why Canadians should focus on meeting the health care needs of the refugees over resettlement, says Y.Y. Brandon Chen, an assistant professor at the University of Ottawa who specializes in health and migration law.

Breanne England, manager of emergency relief and funds at the Canadian Red Cross who has visited Syria five times, says she sees a lot of chronic conditions, including diabetes, cancer and respiratory diseases. These people need regular medical care and medicine and treatment: "Imagine trying to struggle for five years to get that treatment, or to get access to medicine."

The Canadian Red Cross is supporting mobile clinics in Lebanon and Syria, where there are 7.6 million internally displaced people.

Though media attention has mainly focused on the refugees moving into and across Europe, some humanitarian agencies warn that many of those in dire need remain in Syria. The Red Cross works with the Syrian-Arab Red Crescents who deliver food, supplies and health services through the mobile clinics to 3.5 million people in Syria every month.

"That's a drop in the bucket of how many people are actually in need of assistance," England says.

The evolving situation beyond Syria's borders and into Europe has challenged Médecins Sans Frontières' (MSF) agility as it considers where to put resources, says Dr. Heather Culbert, president of MSF Canada. "It honestly seems like almost every day the situation is changing so it's very difficult for us to plan ahead."

Since the war began, MSF has been providing primary, secondary and tertiary health services, including vaccination, maternal and child health, reconstructive surgery and mental health support. It stepped up its efforts when refugees began migrating by foot or sea to Turkey, Greece and Croatia.

However, the organization's main concern remains with the refugees still in camps just outside Syria's borders, and those internally displaced within Syria. - Shannon Lough, Ottawa, Ont.

CMAJ 2015. DOI:10.1503/cmaj.109-5170 